\title{
Posicionamento angular do atacante em relação ao defensor em futebolistas
}

CDD. 20.ed. 796.011

796.33

\author{
Filipe Manuel CLEMENTE* \\ Micael Santos COUCEIRO** \\ Fernando Manuel Lourenço MARTINS ${ }^{* * *}$ \\ Gonçalo DIAS* \\ Rui Manuel MENDES
}

*Faculdade de Ciências do Desporto e Educação Física, Universidade de Coimbra - Portugal.

**Instituto Superior de Engenharia de Coimbra, Instituto Po-

litécnico de Coimbra - Portugal.

***Institudo de Telecomunicações de Covilhã - Portugal.

****Escola Superior de Educação, Instituto Politécnico de Coimbra - Portugal.

0 presente estudo objetivou analisar as amplitudes angulares do atacante em relação ao defensor ao longo da série temporal de prática, tentando verificar se tal parâmetro contribui para a quebra da estabilidade da díade atacante-defensor. Participaram 11 futebolistas (17,91 $\pm 1,04$ anos de idade) com 8,6 $\pm 1,52$ de anos de prática. De forma a entender a relação da posição entre o atacante e o defensor, procedeu-se ao cálculo do posicionamento angular entre ambos. Para o efeito, considerou-se 0 ângulo $0^{\circ}$ como sendo o ângulo entre o atacante e o defensor quando estes formam uma linha perpendicular à aresta do campo onde se encontra a baliza estando o defensor mais próximo da mesma. Os resultados indicam uma oscilação regular por parte do atacante no sentido de procurar desequilibrar o oponente sendo que, através dessa açãoreação o atacante procura encontrar novas soluções que resultem da exploração do meio e do adversário.

UnITERMos: Tomada de decisão; Dinâmica interpessoal; Posicionamento angular; Futebol.

\section{Introdução}

A sistematização do jogo em subsistemas/unidades/ subfases funcionais permite analisar o mesmo com base nas relaçôes intra e inter-acoplamento que se estabelecem entre jogadores (MCGARRY, ANDERSON, Wallace, Hughes \& Franks, 2002). Deste modo, as interaçôes que se estabelecem entre jogadores no decorrer do jogo através de subfase de jogo (e.g., 1x1, $2 \times 2,3 \times 3)$ podem ser estudadas tendo como base a simetria atacante-defensor, emergente do contexto.

Perante a interação constante entre jogadores, constata-se que o atacante procura destabilizar a simetria com o defensor sendo que, inversamente, o defensor procura manter a estabilidade da díade criada entre atacante-defensor, no sentido de assegurar a manutenção do estado de ordem e, consequentemente, a proteção da zona defensiva (MCGARRY, 2005). Desta forma, desportos como o futebol, em que existem situações de oposição e cooperaçãooposição, caracterizam-se como sistemas dinâmicos que deambulam entre estabilidade (i.e., manutenção da simetria atacante-defensor) e instabilidade (i.e., quebra da simetria atacante-defensor). Resultante deste processo dinâmico, importa analisar e destacar os fatores que contribuem para o sucesso do atacante ou do defensor no decorrer das suas funções.

Vários estudos que investigaram as situações de $1 \mathrm{x} 1$ em desportos coletivos (e.g., basquetebol, "rugby", futebol) em consonância com a abordagem dos constrangimentos (NEwELL, 1986) mostram que o envolvimento, as características da tarefa e do jogador são fatores que interagem entre si para o desempenho de habilidades motoras ou movimentos (e.g., Araújo, 2006; Duarte, Araújo, Gazimba, Fernandes, Folgado, Marmeleira \& Davids, 2010a; Duarte, Freire, Gazimba \& Araújo, 2010b; Passos, Araújo, Davids, Gouveia, Milho \& Serpa, 2008; Passos, Araújo, Davids, Gouveia \& Serpa, 2006a; Passos, Lopes \& Milho, 2008).

No caso do basquetebol, numa subfase de jogo $1 \mathrm{x} 1$, apesar dos constrangimentos impostos, os dados obtidos mostraram um padrão de interação onde a coordenação é, predominantemente simétrica, i.e., 
ambos os membros da díade aproximavam-se ou afastavam-se sensivelmente no mesmo momento em relação ao cesto (ARAÚJO, 2006). O autor vai mais longe, afirmando que os estados de simetria são estados de grande atração, impelindo o sistema a manter-se neles, mesmo quando existem quebras de simetria. No entanto, o sucesso do atacante relaciona-se, em grande parte, com a destabilização do estado de simetria e quebra da manutenção do estado de ordem.

No sentido de percecionar os fatores que contribuem para o sucesso ofensivo (i.e., quebra da estabilidade da díade atacante-defensor), um estudo no "rugby" sugere que a distância interpessoal assume-se como um parâmetro de controlo que, individualmente não explica a emergência de novos comportamentos provenientes da quebra da díade, mas que pode servir como parâmetro potenciador da quebra da díade atacante-defensor (PASSOS, LOPES $\&$ MiLho, 2008).

Num estudo com futebolistas (DUARTE et al., 2010a), verifica-se um novo contributo na identificação de fatores potenciadores da quebra da díade atacante-defensor. De fato, os dados resultantes do estudo sugerem que a transição de fase (i.e., quebra da estabilidade da díade) se relaciona com os valores menores de distância interpessoal, bem como, com os maiores valores de velocidade relativa. Quando esses dois parâmetros foram expressos numa única variável, os picos máximos relacionavam-se precisamente com o momento da transição de fase (DUARTE et al., 2010a).

\section{Método}

\section{Participantes}

Participaram no estudo 11 jogadores de futebol do gênero masculino, juvenis e juniores de equipes portuguesas de competição federada distrital, com $17,91 \pm 1,04$ anos de idade e com média de anos de prática de 8,6 $\pm 1,52$ anos. Todos os sujeitos participaram voluntariamente, assinando um termo de consentimento livre e esclarecido. O estudo foi realizado em conformidade com o código de ética da Universidade de Coimbra e as recomendações da Declaração de Helsínque em Pesquisa com Seres Humanos. Os participantes não sofriam de qualquer tipo de incapacidade física ou mental.
Tendo em conta que a tomada de decisão no futebol pode ser influenciada pela distância interpessoal e pela velocidade relativa entre jogadores (DUARTE et al., 2010b; Passos, Lopes \& Milho, 2008), sabendo ainda que as díades atacante-defensor têm sido analisadas principalmente com base na velocidade relativa e distância interpessoal ao longo de séries temporais, este estudo pretende investigar o posicionamento angular do atacante face ao defensor ao longo da situação ofensiva de $1 \mathrm{x} 1 \mathrm{com}$ goleiro, na tentativa de identificar um novo parâmetro de controle que contribui para a transição de fase, resultante no sucesso ofensivo do atacante.

Efetivamente, considera-se que a oscilação angular do posicionamento do atacante em função do defensor direto poderá consubstanciar um parâmetro contribuidor para a compreensão dos processos que resultem num acréscimo de eficácia por parte dos jogadores em ação ofensiva. Igualmente, afigura-se pertinente verificar se o processo de oscilação é linear ou se, pelo contrário, diverge ao longo do tempo e de tentativa para tentativa. De fato, sugere-se que a tomada de decisão na ação ofensiva constituiu-se como um processo emergente que depende dos constrangimentos contextuais e da perceção dos mesmos. Consequentemente, o presente estudo procura acrescentar à distância interpessoal e à velocidade relativa, um indicador de sucesso da ação ofensiva que se relaciona diretamente com a procura do desequilíbrio do defensor aquando de situações de 1x1.

\section{Tarefa}

A tarefa consistiu na concretização do ensaio ofensiva no futebol (i.e., gol) por parte do atacante em situação de $1 x 1$ com goleiro.

\section{Desenho experimental}

Implementou-se uma situação de subfase ao nível do jogo de futebol (i.e., $1 \times 1$ com guarda-redes), num espaço de prática com dimensôes de 19,6 m de largura por $18 \mathrm{~m}$ de comprimento, demarcado com sinalizadores nas extremidades do espaço de prática (cf. FIGURA 1). 


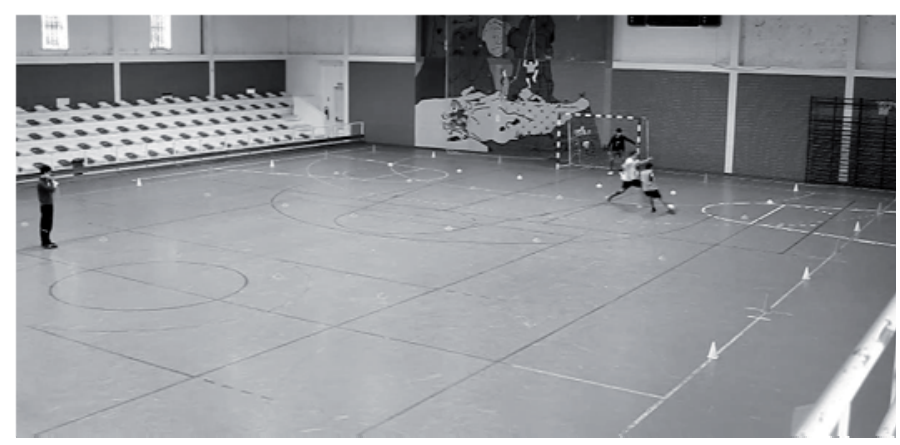

FIGURA 1 - Dispositivo experimental e posicionamento dos jogadores na área de jogo.

$\mathrm{Na}$ condição inicial, o defensor encontrava-se a 6 $\mathrm{m}$ de distância do atacante, estando posicionado no centro do campo, distando $18 \mathrm{~m}$ em relação à baliza. $\mathrm{O}$ goleiro encontrava-se restringido à sua linha de baliza.

\section{Condições da tarefa}

Os jogadores interagiram em situaçóes de $1 \times 1$ com goleiro, sendo que todos os participantes desempenharam funçôes de goleiro, defesa e atacante.

Cada participante realizou a tarefa sob influência de três tipos de constrangimentos instrucionais: 1) conservador; 2) risco e; 3) neutro. Na instrução conservadora, $\mathrm{o}$ atacante foi informado que a sua equipe se encontrava a vencer e, deste modo, deveria atacar e finalizar quando surgisse a melhor oportunidade para tal. A instrução de risco consistiu em informar $o$ atacante que o jogo terminaria brevemente e que a sua equipe se encontrava em desvantagem no resultado e, por conseguinte, deveria arriscar. Por último, na instrução neutra, o atacante foi informado que deveria procurar marcar gol. Quanto ao defensor foi instruído para procurar desarmar o adversário em qualquer uma das situações, evitando o sucesso ofensivo. No fundo, a análise do presente trabalho enfatiza o processo ofensivo e tomadas de decisão a si associadas pelo que, o defensor, em qualquer uma das situaçôes deveria agir de forma a impossibilitar a concretização e ação adversária, visto a informação sob forma de constrangimento apenas ter sido facultada ao atacante.

Em cada uma das três condiçōes de prática (i.e., conservadora, risco e neutra) realizaram-se 10 ensaios, perfazendo 30 ensaios ofensivos por participante. Previamente à realização do estudo concedeu-se a cada participante uma tentativa ofensiva, não contabilizada, de forma a enquadrá-lo com a prática.
Em cada condição de prática, o atacante era informado para concretizar o ensaio ofensivo através de remate (i.e., marcar gol). Por seu lado, o defensor recebia informação para impedir a marcação do gol. Antes do início de cada ensaio, forneceu-se a instrução convencionada (i.e., conservadora, risco ou neutra), sendo que a partir desse momento o atacante poderia iniciar o seu ensaio. Todos os ensaios seguiram as regras do futebol federado para a faixa etária anteriormente referida.

\section{Instrumentos}

Para a filmagem das açōes dos jogadores foi utilizada uma câmara digital SLR (Canon EOS 500D) com capacidade para processar imagens a $30 \mathrm{~Hz}$ (i.e., 30 imagens por segundo). Esta foi colocada a 4,53 m acima do solo, no plano sagital à realização da tarefa (cf. FIGURA 1). Utilizaram-se bolas regulamentadas pela Federação Portuguesa de Futebol para a faixa etária dos jogadores. Um colete laranja e um amarelo foram utilizados, respectivamente, pelo atacante e defesa na situação de prática motora descrita anteriormente. $\mathrm{O}$ mapeamento dos jogadores foi elaborado através do MATLAB.

\section{Procedimentos}

Após a recolha dos ensaios através da filmagem, calibrou-se o espaço de prática utilizando o método DLT de transformaçóes lineares diretas, onde se relacionou a posição do objeto (i.e., jogadores) no espaço em unidades métricas com o objeto correspondente ao plano da imagem em píxels (DUARTE et al., 2010a).

Após a calibração procedeu-se ao mapeamento manual dos jogadores em intervalos de 0,12 segundos, resultando em coordenadas de cada jogador (i.e., atacante e defensor) nos eixos das abcissas e ordenadas. 


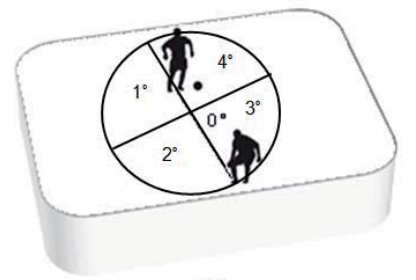

a)

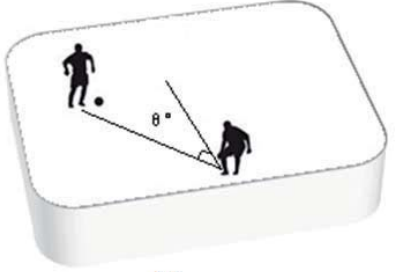

b)

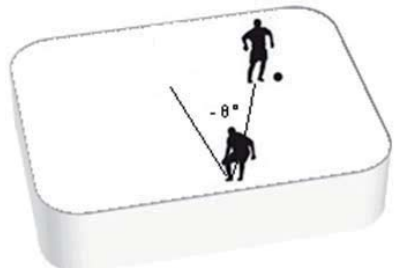

c)

FIGURA 2 - Representação gráfica do posicionamento angular do atacante face ao defensor.

De forma a entender a relação da posição entre o atacante e o defensor, procedeu-se ao cálculo do posicionamento angular entre ambos. Para o efeito, considerou-se o ângulo $0^{\circ}$ como sendo o ângulo entre o atacante e o defensor quando estes formam uma linha perpendicular à aresta do campo onde se encontra a baliza estando o defensor mais próximo da mesma (FIGURA 2a). A forma como o ângulo cresce ou decresce

\section{Resultados}

Através do mapeamento dos jogadores no espaço de prática, identificando-se temporalmente os momentos em que o atacante ultrapassou o defensor e como essa quebra do estado de ordem resultou no referencial angular em relação ao defensor. No presente trabalho a análise realiza-se sob forma individual, i.e., cada jogador foi analisado individualmente, sendo que, os resultados evidenciam o exemplo descritivo dos acontecimentos, equivalente a um ensaio ofensivo. Efetivamente, considera-se que a análise média dos eventos poderá reduzir as hipóteses de compreensão sobre os parâmetros que contribuem para uma ação individualizada visto cada praticante possuir ações específicas que se diferenciam dos restantes. De fato, a média poderia originar interpretaçôes incorretas visto 11 pontos divergentes poderem resultar num espaço não comum mas apenas advindo do encontro médio dos resultados e posicionamentos angulares.

Verifica-se que nos momentos de quebra da díade atacante-defensor (i.e., momento em que a distância em relação à baliza por parte do atacante é menor do que o do defensor, correspondendo aos 2,67 e 2,83 segundos) existem as maiores amplitudes angulares do atacante $\left(104,27^{\circ}\right.$ e $\left.102,1^{\circ}\right)$ em relação ao defensor (cf. FIGURA 3), diminuindo gradualmente face à recuperação da posição do defensor. Constata-se, igualmente, que após o momento da maior amplitude angular (i.e., $104,27^{\circ}$ ) ocorre a maior distância invertida da quebra da díade (i.e., segue os princípios básicos do círculo trigonométrico sendo a origem do referencial o defensor e o eixo dos cosenos a linha perpendicular à aresta onde se encontra a baliza e que passa pelo defensor (FIGURA 2a).

Isto significa que, quando o atacante ultrapassa $o$ defensor, i.e., quando este se encontra mais próximo da baliza, o ângulo irá encontrar-se situado no $2^{\circ}$ e no $3^{\circ}$ quadrante, ou seja, $90^{\circ}<|\theta| \leq 180^{\circ}$ (FIGURA 2a).

$0,20 \mathrm{~m}$ ), i.e., o momento em que o atacante se encontra mais próximo da baliza do que o defensor, distanciado por $0,20 \mathrm{~m}$. No entanto, tal distância não assegurou a concretização total da ultrapassagem do defensor, motivo pelo qual existe de imediato um reposicionamento do defensor e reequilíbrio da simetria da díade atacante-defensor.

À semelhança da situação anterior, verifica-se que durante os momentos em que existe quebra do equilíbrio da díade atacante-defensor, surgem as maiores amplitudes angulares (FIGURA 4). Constata-se ainda que nos 4,67 e 4,83 segundos ocorrem as maiores amplitudes angulares (respectivamente, $159,40^{\circ}$ e $163,80^{\circ}$ ) e a maior diferença de distâncias no momento da quebra da díade entre $\mathrm{o}$ atacante e defensor (i.e., momento em que o atacante se encontra mais próximo da baliza do que o defensor), respectivamente $1,17 \mathrm{~m} \mathrm{e} 0,99 \mathrm{~m}$. Verifica-se, também, que após o momento da maior distância da quebra da díade (i.e., $1,17 \mathrm{~m}$ ), segue-se a maior amplitude angular (i.e., $163,80^{\circ}$ ).

Apesar de neste caso não existir quebra do equilíbrio da díade (cf. FIGURA 5), verifica-se que nos momentos de maior proximidade do atacante face ao defensor (i.e., 3,33 a 3,67 segundos) existem as maiores variações de amplitude na fase de transição (i.e., diferença da amplitude final e inicial contabilizada), neste caso $64,83^{\circ}$, para além de se registarem as maiores amplitudes positivas (i.e., $42,91^{\circ}$ ) e negativas (i.e., $-21,92^{\circ}$ ). 


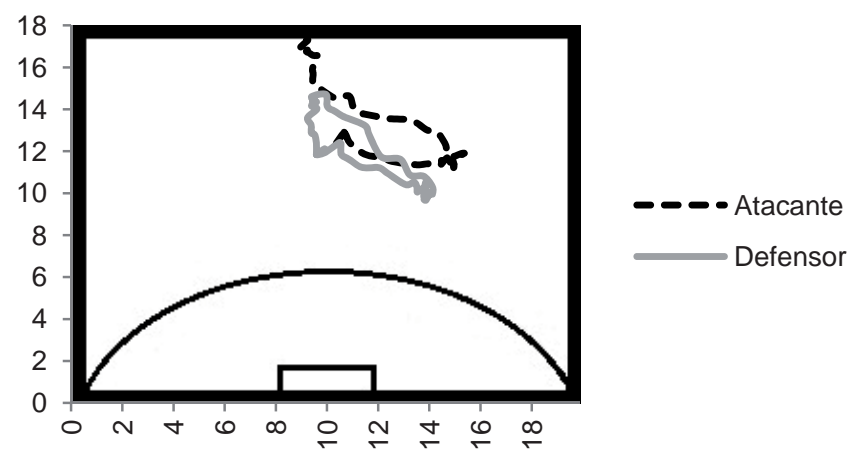

Distância em relação à baliza

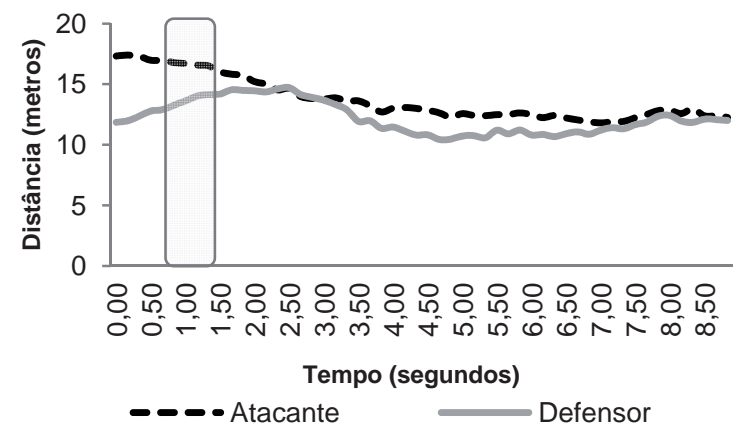

Posicionamento angular do atacante

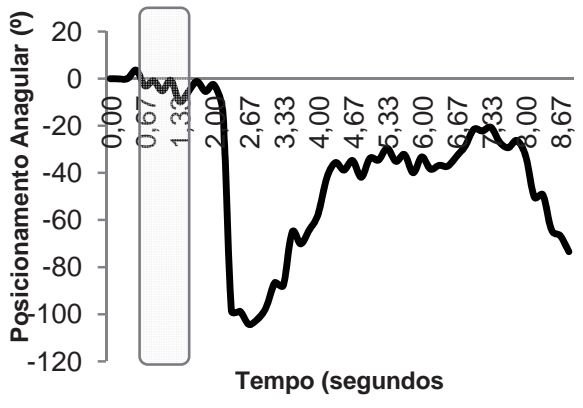

FIGURA 3 - Exemplo de representação gráfica do posicionamento angular do atacante face ao defensor sob o constrangimento instrucional conservador.
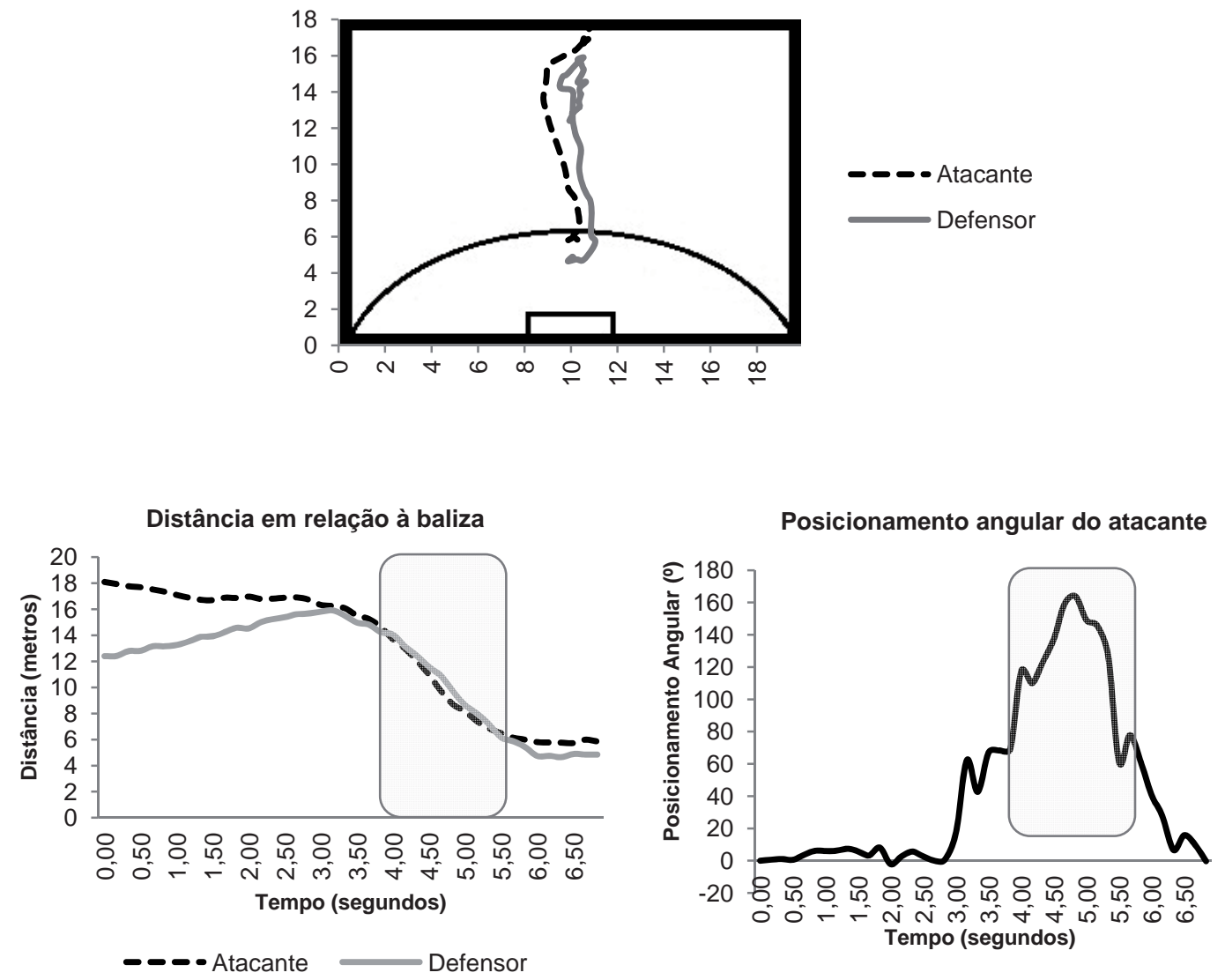

FIGURA 4 - Exemplo de representação gráfica do posicionamento angular do atacante face ao defensor sob o constrangimento instrucional neutral. 

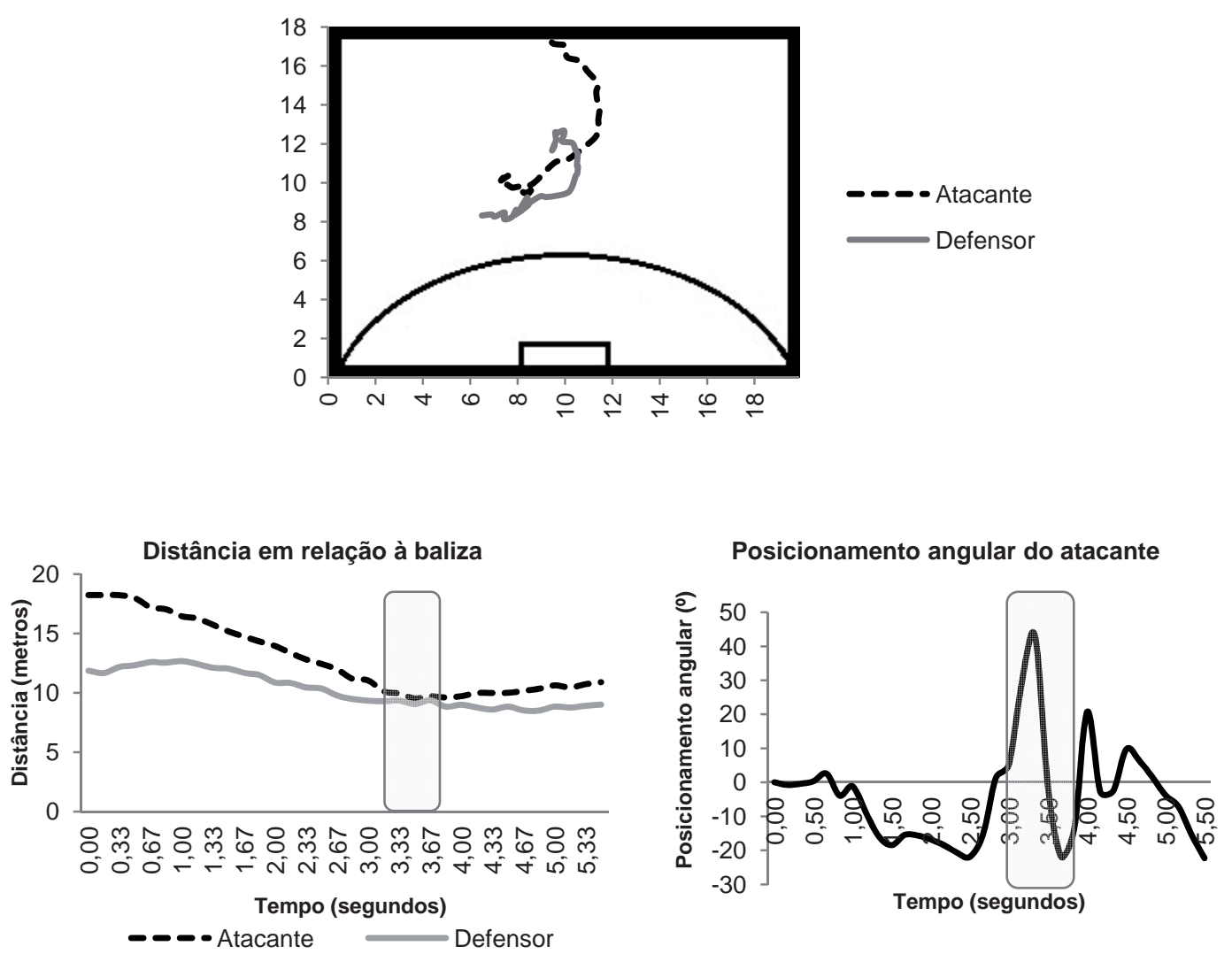

FIGURA 5 - Exemplo de representação gráfica do posicionamento angular do atacante face ao defensor sob o constrangimento instrucional de risco.

\section{Discussão}

O presente trabalho visou identificar um parâmetro de controle que contribuiu para o processo de tomada de decisão do jogador atacante aquando do momento de procura da ação ofensiva sobre o defensor. Os dados obtidos indicam que a tomada de decisão por parte do jogador atacante emerge dum processo contínuo de perceção-ação, sendo que, perante o defensor, o estado de ordem é caracterizado como um processo auto-organizado em concomitância com as interações específicas que contemplam a díade atacante-defensor. Estes resultados confirmam os dados de PASSOS, LOPES e Milho (2008), sustentando que a tomada de decisão em subfases de desportos coletivos de invasão pode ser caracterizada como um processo auto-organizado que resulta da interação sujeito e meio.

A análise da variação angular do atacante face ao defensor mostra que, para que exista transição de fase (i.e., quebra de estabilidade da díade atacante-defensor), é necessário incrementar a variação angular do atacante. Quanto mais próximo da quebra da díade atacante-defensor, maiores amplitudes angulares, por parte do atacante se observam, ou seja, para que exista a ultrapassagem do defensor é fundamental aumentar a amplitude angular em relação ao mesmo.

Constata-se que a amplitude e posição angular do atacante face ao defensor oscila regularmente, resultando de ações contínuas que visam a percepção e novo ciclo perceção-ação, ou seja, o comportamento dificilmente poderá ser determinado antecipadamente, sendo uma resultante emergente da ação e não de programas motores previamente estabelecidos na "cabeça" do jogador (cf. ARAújo, 2006). É por estas razões que a decisão parece emergir do decorrer de ciclos constantes de perceção-ação (DAVIDS, BUTton, Araújo, Renshaw \& Hristovski, 2006). Esta constatação é reforçada no nosso estudo quando os atacantes aumentam a variabilidade das açôes de condução de bola e finta para forçar a emergência de um novo estado de ordem (i.e., transição de fase).

Assim, o sucesso na ação ofensiva do atacante não deve ser atribuído apenas ao treino e padronização 
de ações que reduzem a capacidade criativa e variável de decidir em função de constrangimentos imprevisíveis influenciados pelo ambiente ecológico do jogo (Clemente \& Mendes, 2011). Efetivamente, ao gesto técnico, deve-se adotar, simultaneamente, uma efetiva tomada de decisão que inclui, por exemplo, antecipação, reconhecimento de padrões e reconhecimento de sinais relevantes (e.g., MATIAS \& Greco, 2010; McPherson, 1994; Poolton, Masters \& Maxwell, 2005). É importante desenvolver nos praticantes uma disponibilidade motora e mental que transcenda largamente a simples automatização de gestos e se centre na assimilação de regras de ação e princípios do espaço de jogo, bem como de formas de comunicação e contra comunicação entre os praticantes (GARGANTA, 1995). No fundo, a comprovação de que o praticante age em função dos constrangimentos inerentes a determinada realidade, variando a sua ação e adaptando-se às necessidades vigentes (Clemente, Couceiro, Martins \& Mendes, 2012), sugere que o processo de ensino e treino deve demarcar-se pela sua variabilidade e ecologia de prática procurando que cada situação reflita a realidade imprevisível e dinâmica do jogo, aumentando ou reduzindo a simplificação das tarefas em função das necessidades de cada aluno ou jogador (Clemente et al., 2012).

O presente estudo propôs-se a estudar o parâmetro de ação de posicionamento angular do atacante face ao defensor. Conclui-se que o atacante na tentativa de ultrapassar o defensor, oscila permanentemente o seu posicionamento angular em relação ao defensor, procurando a quebra da díade e um novo ciclo de perceção-ação, constituindo-se o posicionamento angular como um parâmetro de ação que contribui para emersão da decisão. Em suma, a tomada de decisão no futebol pode ser influenciada não só pela distância interpessoal e velocidade relativa (DUARTE et al., 2010a), mas também pelo posicionamento angular do atacante face ao defensor (i.e., na tentativa de destabilizar o estado de ordem da díade atacante-defensor).

\section{Abstract}

\section{Angular positioning of attacker over the defender in football players}

The aim of this study was to analyze the angular amplitudes of the attacker over the defender along the series of practice, trying to see if this parameter contributes to the breakdown of the stability of the attacker-defender dyad. In the study participated 11 players (17.91 \pm 1.04 years old) with $8.6 \pm 1.52$ years of practice. In order to understand the position relationship between the attacker and defender, we calculate the angular positioning between them. For this purpose we considered the $0^{\circ}$ angle as the angle between the striker and the defender when they form a perpendicular line to the edge of the field where staying the goal. The results show a regular oscillation by the attacker to seek to unbalance the opponent and that through this action-reaction the attacker tries to find new solutions resulting from the exploitation of the environment and the opponent.

UNITERMS: Decision making; Interpersonal dynamic; Angular positioning; Football.

\section{Resumen}

Posicionamiento angular del atacante en relación al defensor en los futbolistas

El presente estudio tuvo como objetivo analizar las amplitudes angulares del atacante contra el defensor, tratando de ver si este parámetro contribuye a la ruptura de la estabilidad de la pareja atacante-defensor. Participaron 11 jugadores (17,91 \pm 1,04 años), con 8,6 \pm 1,52 años de práctica. Con el fin de entender la relación de posición entre el atacante y el defensor, procedió al cálculo de la posición angular entre los dos. Con este fin, hemos considerado el ángulo de $0^{\circ}$ como el ángulo entre el delantero y el defensor cuando forman una línea perpendicular a la arista del campo donde se encuentra la portería, estando el defensor está más cerca de la misma. Los resultados muestran una oscilación regular del atacante para 
tratar de desequilibrar al oponente siendo que a través de esta acción-reacción, el atacante trata de encontrar nuevas soluciones que resultan de la exploración del ambiente y del adversario.

Palabras clave: Tomada de decisiones; Dinámica interpersonal; Posicionamiento angular; Fútbol.

\section{Referências}

ARAÚJO, D. Tomada de decisão no desporto. Cruz Quebrada: FMH Ediçōes, 2006.

CLEMENTE, F.; COUCEIRO, M.; MARTINS, F.; MENDES, R. The usefulness of small-sided games on soccer training. Journal of Physical Education and Sport, Algebizv.12, n.1, p.93-102, 2012.

CLEMENTE, F; MENDES, R. Aprender o jogo jogando: uma justificação transdisciplinar. Exedra: Revista Científica, Coimbra, v.5, n.1, p.27-36, 2011. Disponível em: <http://www.exedrajournal.com/docs/N5/02A-FClemente_RMendes.pdfs. DAVIDS, K.; BUTTON, C.; ARAÚJO, D.; RENSHAW, I.; HRISTOVSKI, R. Movement models from sports provide representative task constraints for studying adaptive behavior in human movement systems. Adaptive Behavior, Thousand Oaks, v.14, n.1, p.73-95, 2006. Disponível em: <http://dx.doi.org/10.1177/105971230601400103>.

DUARTE, R.; ARAÚJO, D.; GAZIMBA, V.; FERNANDES, O.; FOLGADO, H.; MARMELEIRA, J.; DAVIDS, K. The ecological dynamics of 1v1 sub-phases in Association Football. The Open Sports Sciences Journal, Hilversum, v.3, p.16-18, 2010a. Disponível em: <http://www.benthamscience.com/open/tossj/articles/V003/16TOSSJ.pdf>.

DUARTE, R.; FREIRE, L.; GAZIMBA, V.; ARAÚJO, D. A emergência da tomada de decisão no futebol: da decisão individual para a colectiva. In: NOGUEIRA, C. Psicologia do desporto: actas do VII Simpósio Nacional de Investigação em Psicologia. Minho: Universidade do Minho, 2010b. Disponível em: <http://www.actassnip2010.com/conteudos/actas/PsiDesp_2.pdfs. GARGANTA, J. Para uma teoria dos jogos desportivos colectivos. In: GRAÇA, A.; OLIVEIRA, J. (Eds.). O ensino dos jogos desportivos. Porto: FCDEF-UC, 1995. p.11-25.

MATIAS, C.J.; GRECO, P.J. Cogniçãa \& acção nos jogos esportivos colectivos. Ciências \& Cogniçãa, Rio de Janeiro, v.15, n.1, p.252-71, 2010. Disponível em: <http://www.cienciaecognicao.org/revista/index.php/cec/article/view/123>.

McGARRY, T. Soccer as a dynamical system: some theoretical considerations. In: REILLY, T.; CABRI, J.; ARAÚJO, D. (Eds.). Science and football V. Oxon: Routledge/Taylor \& Francis Group, 2005. p.570-79.

McGARRY, T.; ANDERSON, D.; WALLACE, S.; HUGHES, M.; FRANKS, I. Sport competition as a dynamical self-organizing system. Journal of Sports Sciences, London, v.20, p.771-81, 2002. Disponível em: <http://dx.doi.org/10.1080/026404102320675620>.

McPHERSON, S.L. The development of sport expertise. Quest, Champaign, v.46, n.2, p.223-40, 1994.

NEWELL, K.M. Constraints on the development of coordination. In: WADE, M.G.; WHITING, H.T.A. (Eds.). Motor development in children: aspects of coordination and control. Dordrecht: Martinus Nijhoff, 1986. p.341-60.

PASSOS P.; ARAÚJO, D.; DAVIDS, K;; GOUVEIA, L.;SERPA, S. Interpersonal dynamicsin sport: the role of artificial neural networks and 3-D analysis. Behavior Research Methods, Austin, v.38, n.4, p.683-91, 2006. Disponível em: <http://dx.doi.org/10.3758/BF03193901>. PASSOS, P.; ARAÚJO, D.; DAVIDS, K.; GOUVEIA, L.; MILHO, J.; SERPA, S. Information-governing dynamics of attacker-defender interactions in youth rugby union. Journal of Sports Sciences, London, v.16, n.13, p.1421-9, 2008. Disponível em: <http://dx.doi.org/10.1080/02640410802208986>.

PASSOS, P.; LOPES, R.; MILHO, J. Análise de padrōes de coordenação interpessoal no um-contra-um no Futebol. Revista Portuguesa de Ciência do Desporto, Porto, v.8, n.3, p.365-76, 2008. Disponível em: <http://www.scielo.oces.mctes.pt/ scielo.php?pid=S1645-05232008000300007\&script=sci_arttext>.

POOLTON, J.M.; MASTERS, W.S.R.; MAXWELL, P.J. The relationship between initial errorless learning conditions and subsequent performance. Human Movement Science, Amsterdam, v.24, n.3, p.362-78, 2005.

Filipe Manuel Batista Clemente

Faculdade de Ciências do Desporto e Educação Física

Universidade de Coimbra

Estádio Universitário - Pavilhão 3

3040-156 - Coimbra - PORTUGAL

e-mail: filipe.clemente5@gmail.com

Recebido para publicação: 16/ 01/ 2012

Revisado: 09/05/2012

Aceito: 25/ 05/2012 